\title{
Induction of MicroRNA-24 by HIF-1 Protects Against Ischemic Injury in Rat Cardiomyocytes
}

\author{
D.-F. LI ${ }^{1, \#, ~ J . ~ T I A N ~}{ }^{1, \#}$, X. GUO ${ }^{2}$, L.-M. HUANG ${ }^{2}$, Y. XU ${ }^{1}$, C.-C. WANG ${ }^{1}$, J.-F. WANG ${ }^{2}$, \\ A.-J. REN ${ }^{1}$, W.-J. YUAN ${ }^{1,2}$, L. LIN ${ }^{1}$ \\ ${ }^{\#}$ Dong-Feng Li and Jing Tian contributed equally to this work.
}

${ }^{1}$ Department of Physiology and the Key Laboratory of Molecular Neurobiology of Ministry of Education, Second Military Medical University, Shanghai, P. R. China, ${ }^{2}$ Department of Physiology and Neurobiology, Basic Medical College, Ningxia Medical University, Yinchuan, P. R. China

Received October 15, 2011

Accepted July 23, 2012

On-line October 25, 2012

\begin{abstract}
Summary
MicroRNAs are emerging as important regulators of cardiac function. This study investigated the role of microRNA-24 (miR-24) in ischemic cardiomyocytes, based on the observation that miR-24 expression was significantly enhanced in the ischemic myocardium of rats. Using primary cultured rat cardiomyocytes, cell injury was induced by ischemic conditions, and the cells were evaluated for changes in lactate dehydrogenase (LDH) release, cell viability, apoptosis and necrosis. The results showed that miR-24 was increased in myocytes exposed to ischemia. When miR-24 was further overexpressed in ischemic myocytes using the mimic RNA sequence, LDH release was reduced, cell viability was enhanced, and apoptosis and necrosis rates were both decreased. By contrast, a deficiency in miR-24 resulted in the largest LDH release, lowest cell viability and highest apoptosis and necrosis rates in normal and ischemic myocytes, with significant changes compared to that of non-transfected myocytes. Additionally, the mRNA and protein levels of the pro-apoptotic gene, BCL2L11, were down-regulated by miR-24 overexpression and up-regulated by miR-24 deficiency. The luciferase reporter assay confirmed BCL2L11 to be a target of miR-24. Overall, this study showed a protective role for miR-24 against myocardial ischemia by inhibiting BCL2L11, and may represent a potential novel treatment for ischemic heart disease.
\end{abstract}

\section{Key words}

MicroRNA • Myocardial ischemia • Apoptosis • Cardiomyocytes

\section{Corresponding authors}

L. Lin and W.-J. Yuan, Department of Physiology, Second Military Medical University, 800 Xiangyin Road, Shanghai 200433, P. R. China. Tel./Fax: +86-21-81870983. E-mail: lilincn@hotmail.com or yuanwj@hotmail.com

\section{Introduction}

Coronary disease is one of the most prevalent diseases afflicting humans (He et al. 2005). The major consequences of coronary disease are myocardial ischemia (cell damage) and myocardial infarction (cell death and apoptosis), either of which can develop when blood supply to the myocardium decreases. Myocardial infarction is a complex process for which the regulatory mechanisms remain to be understood. Recent studies have indicated the active involvement of microRNAs (miRNAs) in numerous heart diseases, including myocardial infarction (Latronico et al. 2007, Van Rooij et al. 2007, Ye et al. 2011).

MiRNAs are a class of endogenous, small noncoding single-stranded RNAs, about 22 nucleotides in length, with highly conserved sequences among species (Bartel 2004). There are approximately 500 known mammalian miRNAs, and each miRNA may regulate hundreds of protein-coding genes (Lewis et al. 2005). MiRNAs regulate gene expression mainly through interaction with the 3'-untranslated region (UTR) of the target mRNA, resulting in mRNA degradation or the inhibition of protein translation (Filipowicz et al. 2008). 
Accumulative data suggest that miRNAs are extensively involved in the pathological processes of the heart, including cardiac hypertrophy (Carè et al. 2007, Song et al. 2010), heart failure (Thum et al. 2007), arrhythmia (Yang et al. 2007) and myocardial ischemia and reperfusion (Dong et al. 2009, Hu et al. 2010, Qian et al. 2011). However, due to the multiplicity of miRNAs and their potential regulation of a large proportion of target genes, the function of most of these miRNAs is scarcely known. We identified an aberrantly expressed miRNA, miR-24, in the ischemic myocardium of intact rats, based on a miRNA array analysis (Fang et al. 2011). The present study investigated the role of miR-24 in myocardial ischemia.

\section{Materials and Methods}

\section{Rat model of acute myocardial ischemia}

The rat model of myocardial ischemia was prepared as we described previously (Lin et al. 2002). Briefly, male Sprague-Dawley rats (260-330 g) were anesthetized with sodium pentobarbitone $(60 \mathrm{mg} / \mathrm{kg}$, intraperitoneally), and a tracheotomy was performed to maintain a patent airway. One femoral artery was cannulated to monitor arterial blood pressure (BP) and the left ventricle was cannulated to record left ventricular pressure (LVP). A standard limb lead I electrocardiogram (ECG) was continuously monitored. A left thoracotomy was performed and artificial respiration was carried out at a stroke volume of $1.5 \sim 2 \mathrm{ml} / 100 \mathrm{~g}$ and a rate of 60 strokes/min to maintain arterial $\mathrm{PCO}_{2}, \mathrm{PO}_{2}$ and $\mathrm{pH}$ within the normal range. The heart was exposed, a $6 / 0$ braided silk suture was placed around the initial segment of the left anterior descending coronary artery (LAD), and then tied off after $15 \mathrm{~min}$ stabilization to induce LAD occlusion. Myocardial ischemia was confirmed by profound decreases in BP and LVP, changes in ECG, and visual cyanosis of the topical heart. After $4 \mathrm{~h}$ of occlusion, the ischemic tissue was dissected and processed to determine miR-24 expression levels.

All animal procedures were approved by the Second Military Medical University, China, in accordance with the Guide for Care and Use of Laboratory Animals published by the US NIH (publication No. 96-01).

\section{Mimic ischemia in cultured cardiomyocytes}

A primary culture of ventricular myocytes from neonatal Sprague-Dawley rats was prepared, as we described previously (Pan et al. 2007). Briefly, the heart ventricles were dissected and digested with $0.2 \%$ trypsin (Amresco, Solon, OH, USA). Cells were filtered through a nylon mesh, resuspended in Dulbecco's Modified Eagle Medium (DMEM; Sigma-Aldrich, St. Louis, MO, USA) containing $0.45 \%$ glucose, $10 \%$ neonatal bovine serum and $10 \%$ fetal bovine serum, pre-plated for $30 \mathrm{~min}$, seeded at the concentration of $5 \times 10^{5}$ cells $/ \mathrm{ml}$, and cultured in a humidified atmosphere of $5 \% \mathrm{CO}_{2}$ at $37^{\circ} \mathrm{C}$. After 3-4 days of culture, the myocytes were serumdeprived for $12 \mathrm{~h}$ to synchronize the growth, and then exposed to mimic ischemia $\left(1 \% \mathrm{O}_{2}, 0.1 \%\right.$ glucose, serum-free) for a further $24 \mathrm{~h}$. The control myocytes were incubated in regular serum-free DMEM containing $0.45 \%$ glucose under normoxia.

Real-time RT-PCR detection of miR-24 and its potential target genes

Total RNA was extracted from rat myocardium and cultured cardiomyocytes with Trizol (Invitrogen, USA) according to the manufacturer's instructions. One microgram of total RNA was reverse-transcribed using M-MLV reverse transcriptase with oligo-dT for mRNAs and a special stem-loop primer for miR-24 (5'GTCGTATCCAGTGCAGGGTCCGAGGTATTCGCAC TGGATACGACCTGTTC-3'), as we described previously (Song et al. 2010). Real-time quantitative PCR was performed on a Rotor-Gene 3000 real-time DNA detection system (Corbett Research, Sydney, Australia) using SYBR Green (Qiagen, Shanghai, China). The relative expression levels of miR-24 and its potential target genes were determined by the standard curve method, and normalized to U6 and GAPDH, respectively. The PCR primers were: 5'-CTGAGTGGCTCAATTCAGCA-3' (forward) and 5'-GTGCAGGGTCCGAGGT-3' (reverse) for miR-24, 5'-CTCGCTTCGGCAGCACA-3' (forward) and 5'-AACGCTTCACGAATTTGCGT-3' (reverse) for U6, 5'-GCTACCAGATCCCCACTTTTCA-3' (forward) and 5'-CCGGGCTCCTGTCTGTGT-3' (reverse) for BCL2L11, and 5'-AACGACCCCTTCATTGACCTC-3' (forward) and 5'-CCTTGACTGTGCCGTTGAACT-3' (reverse) for GAPDH.

\section{MiRNA transfection experiments}

To overexpress or knock down miR-24 expression, cultured cardiomyocytes were incubated with miR-24 mimic or inhibitor for $24 \mathrm{~h}$ before the onset of serum-deprivation and the following ischemia. The 
mimic of miR-24 was a duplex RNA, in which the sense sequence (5'-uggcucaguucagcaggaacag-3') was the same as miR-24, and the antisense sequence (5'-guuccugcugaacugagccauu-3') had 2-nt 3'-overhangs and 2-nt 5'-trims. The inhibitor of miR-24 (5'-cuguuccugcugaacugagcca-3') was a single RNA sequence exactly complementary to miR-24. The transfection was performed using siPORT ${ }^{\mathrm{TM}} \mathrm{NeoFX}^{\mathrm{TM}}$ transfection agent (AM4511, Applied Biosystems Inc., USA). Mock-transfection (transfection without RNA) and non-targeting negative control sequences (for mimic: sense 5'-uucuccgaacgugucacgutt-3', antisense 5'-acgugacacguucggagaatt-3'; for inhibitor: 5'-caguacuuuuguguaguacaa-3') were used as controls. All of the above sequences were custom-synthesized by Shanghai GenePharma Co., Ltd, China.

\section{Determination of cell injury and viability}

Cell injury was determined by the release of lactate dehydrogenase (LDH) from cardiomyocytes. $\mathrm{LDH}$ activity in the culture medium was determined using an automatic biochemical analyzer (model 7150, Hitachi, Japan) according to the manufacturer's instructions. Cell viability was determined by 3-(4,5-dimethylthiazol-2-yl)2,5-diphenyl tetrazonium bromide (MTT) assay based on the formation of formazan from MTT by metabolically active cells, as described in our previous work (Pan et al. 2007, Zheng et al. 2010). MTT (Amresco, USA) was added to the medium at a final concentration of $0.5 \mathrm{mg} / \mathrm{ml}$ for the last $12 \mathrm{~h}$ of the experiment. The resulting formazan crystals were dissolved in dimethyl sulfoxide and the optical absorbance was measured on a microtitre plate reader (Bio-Rad 550, USA). Cell viability was presented as a percentage of the control absorbance (untreated cells) after subtracting the background absorbance of culture medium without cells.

Analysis of cell apoptosis

Cell apoptosis was detected by Hoechst 33258 dye staining (Hoechst 33258 kit, Beyotime, Jiangsu, China) and Annexin V-FITC/propidium iodide (AV/PI) dual staining with a commercial kit (Bender MedSystems, USA), as we reported previously (Zheng et al. 2010). Both staining procedures were performed in accordance with the manufacturers' instructions.

In the Hoechst staining procedure, cultured cardiomyocytes were fixed with paraformaldehyde, stained with Hoechst 33258, a membrane-permeable nuclear dye, and examined under an Olympus fluorescence microscope (Olympus, Tokyo, Japan). Apoptotic cells were identified based on nuclear condensation and fragmentation, and the percentage of apoptotic cells versus total cells was calculated.

In the AV/PI staining procedure, the cultured cardiomyocytes were digested with trypsin, washed, dualstained with AV and PI according to the manufacturer's instructions, and then analyzed by flow cytometry on a BD FACSCalibur (Becton Dickinson Co., Becton Dickinson Co., Franklin Lakes, NJ, USA). This dual staining can discriminate intact cells $\left(\mathrm{AV}^{-} / \mathrm{PI}^{-}\right)$, early apoptotic/apoptotic cells $\left(\mathrm{AV}^{+} / \mathrm{PI}^{-}\right)$, late apoptotic/ necrotic cells $\left(\mathrm{AV}^{+} / \mathrm{PI}^{+}\right)$, and necrotic cells $\left(\mathrm{AV}^{-} / \mathrm{PI}^{+}\right)$.

Western blot analysis of the potential target genes of miR-24

Protein levels of HIF-1 $\alpha$, a subunit of HIF-1 that putatively activates the promoter of miR-24-1 gene, and of BCL2L11, a potential target gene of miR-24, were determined by western blotting. Briefly, primary cultured cardiomyocytes were lysed with RIPA buffer (Beyotime, Jiangsu, China), sonicated on ice, and the protein concentration determined using the bicinchoninic acid kit (Beyotime, Jiangsu, China). Total protein $(20 \mu \mathrm{g})$ were electrophoresed on a $10 \%(\mathrm{w} / \mathrm{v})$ SDS-PAGE gel, transferred onto a nitrocellulose membrane and blocked with $5 \%(\mathrm{w} / \mathrm{v})$ non-fat dried milk. Membranes were probed with the primary antibody against HIF-1 $\alpha$ or BCL2L11 (Santa Cruz Biotechnology, CA, USA), followed by the appropriate peroxidase-conjugated secondary antibody. Protein signal was visualized by chemiluminescence reagents under a GeneGnome Bio Imaging System (Syngene, MD, USA). The amount of protein in each blot was quantified by densitometry and normalized to GAPDH, an internal standard.

Construction of luciferase reporter plasmid and analysis of luciferase activity

To examine whether miR-24 regulates the expression of BCL2L11, the dual luciferase psiCheck2 reporter plasmid (Promega, Madison, WI, USA) was used to generate the reporter plasmid harboring BCL2L11 3'-UTR, as we described previously (Fang et al. 2011). Briefly, a 329-bp fragment of BCL2L11 (NM_138621) 3'-UTR containing the putative miR-24 binding site was amplified from rat genomic DNA by PCR, using the primers 5'-ACAATTGTCTGCCGTTTCCC-3' and 5'-GAGTGGGAGACAGGGATGTT-3', and cloned into 
the multiple cloning region located at the 3'-UTR of the synthetic Renilla luciferase gene within the psiCheck2 plasmid, which also contains a synthetic firefly luciferase gene that serves as the transfection control.

The psiCheck2 vector containing BCL2L11 3'-UTR was co-transfected with miR-24 mimic into 293T cells using Lipofectamine 2000 (Invitrogen, Carlsbad, CA, USA), or with non-targeting negative control RNA as control. The cells were harvested after $24 \mathrm{~h}$ transfection, and measured with luciferase activity using a dual luciferase reporter assay kit (Promega, Madison, WI, USA) on a luminometer.

\section{Statistical analysis}

All data are expressed as the mean \pm S.D. and were analyzed with one-way ANOVA followed by the Fisher's least significant difference (LSD) test to determine the differences between groups. SAS 9.0 statistical software (SAS Institute Inc., USA) was used for data analysis. Two-tailed $(\mathrm{P}<0.05)$ was considered statistically significant.

\section{Results}

\section{A HIF-1 $\alpha$-dependent increase of miR-24 expression in} ischemic cardiomyocytes

As we reported recently (Fang et al. 2011), the expression level of miR-24 in the ischemic myocardium after $4 \mathrm{~h}$ of LAD occlusion in intact rats, as detected by miRNA microarray analysis, was significantly upregulated by 1.96-fold compared with that of the shamoperated control rats. The real-time RT-PCR analysis showed an increase of 1.76-fold for miR-24 in the ischemic myocardium (Fig. 1A).

In primary cultured rat cardiomyocytes exposed to mimic ischemia, miR-24 expression also significantly increased by 1.49 -fold after $12 \mathrm{~h}$, by 1.93 -fold after $24 \mathrm{~h}$, and by 1.64 -fold after $48 \mathrm{~h}$ (Fig. 1B). Since the level of miR-24 reached the highest after $24 \mathrm{~h}$, all of the other experiments were performed in cardiomyocytes exposed to $24 \mathrm{~h}$ of mimic ischemia.

To explore the mechanism for miR-24 upregulation, we examined the regulation of miR-24 expression by hypoxia-inducible factor (HIF), a key transcription factor activating the transcription of genes involved in adaptation to hypoxia. HIF is a heterodimer consisting of one of the three $\alpha$-subunits (HIF- $1 \alpha$, HIF- $2 \alpha$ and HIF-3 $\alpha$ ) and the constitutively expressed $\beta$-subunit HIF-1 $\beta$ (Berra et al. 2003). The $\alpha$-subunit is oxygen
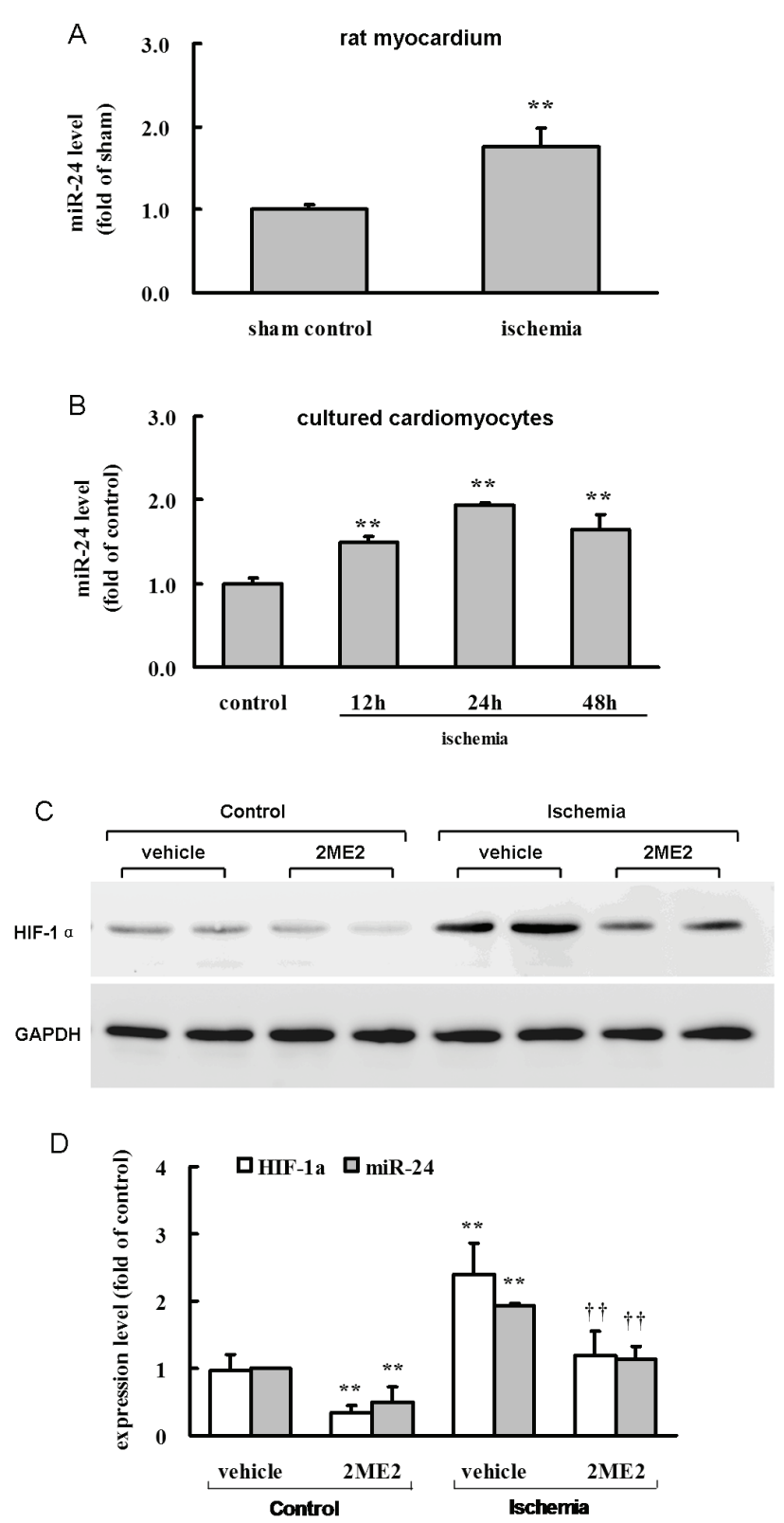

Fig. 1. (A) Increased miR-24 levels in ischemic rat myocardium after $4 \mathrm{~h}$ of LAD occlusion, as determined by real-time RT-PCR. (B) Increased miR-24 levels in primary cultured neonatal rat cardiomyocytes exposed to mimic ischemia $\left(1 \% \mathrm{O}_{2}, 0.1 \%\right.$ glucose, serum-free). (C) Representative western blot images for HIF-1a and GAPDH in cultured cardiomyocytes pretreated with $20 \mu \mathrm{M}$ of 2-methoxyestradiol (2ME2) for $30 \mathrm{~min}$ prior to ischemic exposure for 24 h. (D) Quantitative data of HIF-1a protein levels determined by western blot (C) and miR-24 levels determined by real-time RT-PCR in cardiomyocytes receiving 2ME2. Values are means \pm S.D. ( $n=4$ for each group). ${ }^{* * P}<0.01$ vs. control; ${ }^{\dagger} \mathrm{P}<0.05,{ }^{+\dagger} \mathrm{P}<0.01$ vs. ischemia.

labile, but rapidly stabilized in response to low oxygen tension. HIF-1 was previously described to robustly activate the promoter of miR-24-1 (there are two genomic loci encoding miR-24, miR-24-1 and miR-24-2) in a cancer cell line, as shown by luciferase reporter assays (Kulshreshtha et al. 2007). In the present study, we 
treated cardiomyocytes with 2-methoxyestradiol (2ME2),

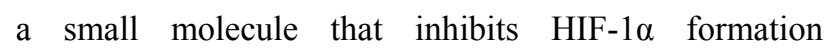
(Mabjeesh et al. 2003), and observed that the protein level of HIF-1a was significantly reduced by 2ME2 in both control and ischemic myocytes, and a lower level of HIF-1a was accompanied by a lower level of miR-24 (Fig. 1C,D). The ischemia-induced increase in miR-24 was totally abolished by $2 \mathrm{ME} 2$ (Fig. 1D), suggesting that the induction of miR-24 expression by ischemia was dependent on HIF-1.
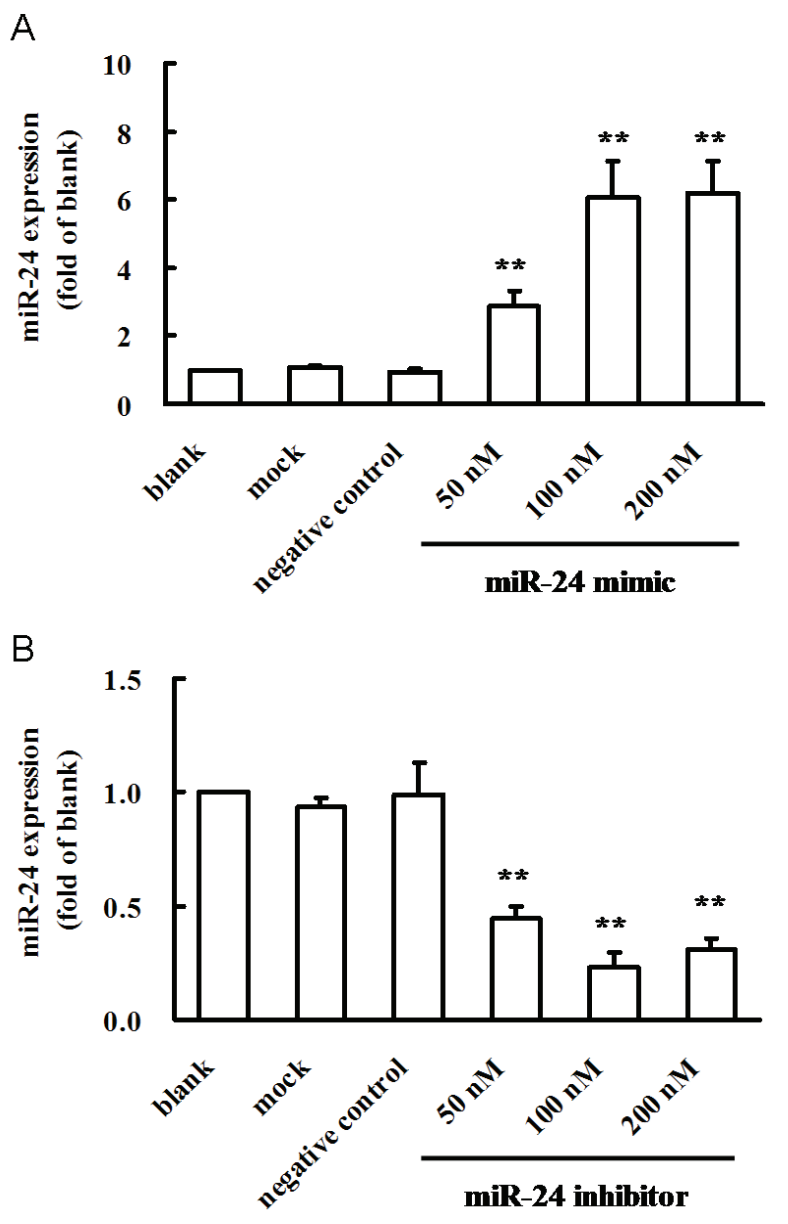

Fig. 2. miR-24 expression levels determined by real-time RT-PCR in primary cultured neonatal rat cardiomyocytes transfected with the miR-24 mimic (A) or inhibitor (B). The transfection was performed with the aid of transfection agent for $24 \mathrm{~h}$. Mocktransfection (transfection without RNA) and non-targeting negative control RNAs were used as controls. Data are presented as means \pm S.D. from four independent experiments. ${ }^{*} * P<0.01$ vs. blank.

miR-24 expression was regulated by its mimic and inhibitor

In cultured myocytes, transfection of miR-24 mimic or inhibitor significantly increased or decreased the level of miR-24, respectively. Neither the mock nor negative control transfections affected miR-24 expression. A concentration of $100 \mathrm{nM}$ was identified to be optimal for both the mimic and inhibitor of miR-24, with the mimic RNA upregulating miR-24 by 6.04 -fold $(\mathrm{P}<0.01)$, and the inhibitor RNA downregulating miR-24 to 0.23 -fold of the control level $(\mathrm{P}<0.01)$ (Fig. 2).

Protective role of miR-24 against ischemia-induced injury in cultured cardiomyocytes

In normal cultured cardiomyocytes, the level of $\mathrm{LDH}$ release was low $(0.14 \pm 0.03 \mathrm{U} / \mathrm{mg} \cdot \mathrm{pro})$, and transfection of the control RNA or miR-24 mimic did not affect the released amount. However, transfection of the miR-24 inhibitor significantly increased $\mathrm{LDH}$ release (0.25 $\pm 0.02 \mathrm{U} / \mathrm{mg} \cdot$ pro, $\mathrm{P}<0.01$ vs. control), indicating damage to the cell membrane integrity. In the myocytes exposed to $24 \mathrm{~h}$ ischemia, $\mathrm{LDH}$ release was greatly increased $(0.46 \pm 0.05 \mathrm{U} / \mathrm{mg} \cdot$ pro, $\mathrm{P}<0.01$ vs. control), which was attenuated by the miR-24 mimic $(0.24 \pm 0.03$ $\mathrm{U} / \mathrm{mg}$.pro, $\mathrm{P}<0.01$ vs. ischemia), whereas enhanced by the miR-24 inhibitor $(0.75 \pm 0.05 \mathrm{U} / \mathrm{mg} \cdot$ pro, $\mathrm{P}<0.01$ vs. ischemia) (Fig. 3A).

As determined by the MTT assay (Fig. 3B), overexpression of miR-24 using the miR-24 mimic did not affect cell viability in normal culture. However, transfection of the miR-24 inhibitor significantly decreased the viability of normal cultured cells to $77.2 \pm 4.9 \%$ of the control value $(\mathrm{P}<0.01)$. In the myocytes exposed to $24 \mathrm{~h}$ ischemia, cell viability was decreased to $53.7 \pm 9.1 \%$ of normal control values $(\mathrm{P}<0.01)$. Transfection of the miR-24 mimic enhanced this post-ischemic cell viability to $75.3 \pm 5.4 \%$ of normal control values $(\mathrm{P}<0.01$ vs. ischemia $)$. By contrast, transfection of the miR-24 inhibitor further decreased cell viability to $33.5 \pm 5.2 \%$ of normal control values $(\mathrm{P}<0.01$ vs. ischemia). These results indicated the protective role of miR-24 in reducing cell damage and enhancing cell viability under ischemic conditions.

miR-24 inhibited ischemia-induced apoptosis and necrosis in cultured cardiomyocytes

Nuclear staining with Hoechst 33258 (Fig. 4) showed only about $6 \%$ of the nuclei in normal cultured cardiomyocytes had manifested apoptotic characteristics, including nuclear condensation and fragmentation. By contrast, a greater percentage of apoptotic nuclei were observed in cells cultured under ischemic conditions $(22.0 \pm 3.0 \%$ vs. $6.3 \pm 2.1 \%, \mathrm{P}<0.01)$. Transfection of the miR-24 mimic significantly reduced the apoptosis rate to 
A

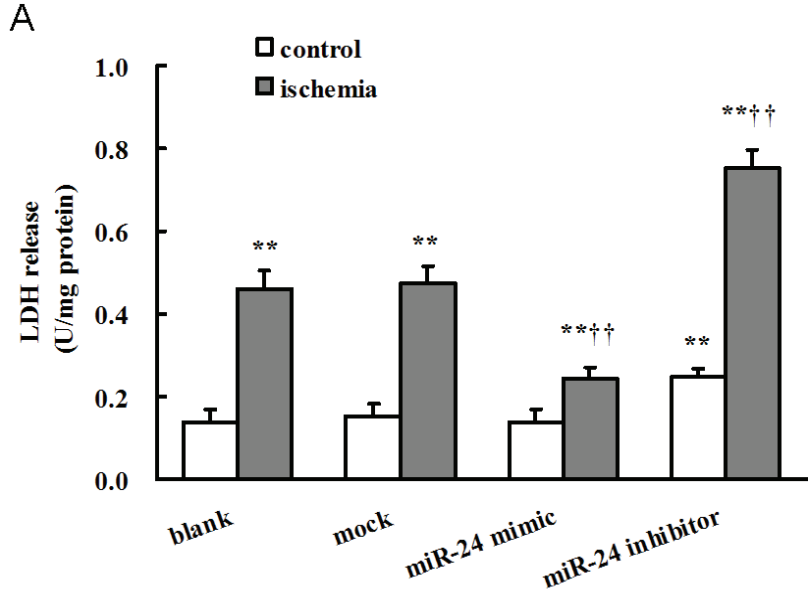

B

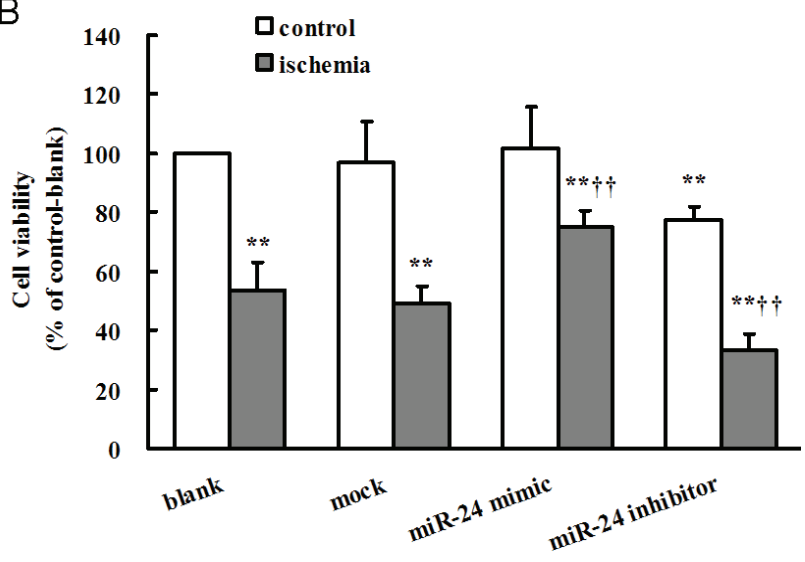

Fig. 3. Lactate dehydrogenase (LDH) release into media (A) and cell viability (B) in primary cultured rat cardiomyocytes transfected with $100 \mathrm{nM}$ of the miR-24 mimic or inhibitor after $24 \mathrm{~h}$ of mimic ischemia $\left(1 \% \mathrm{O}_{2}, 0.1 \%\right.$ glucose, serum-free). Values are means \pm S.D. ( $n=5$ for each group). ${ }^{*} P<0.05$, ${ }^{*} \mathrm{P}<0.01$ vs. control; ${ }^{\dagger} \mathrm{P}<0.05,{ }^{+\dagger} \mathrm{P}<0.01$ vs. ischemia.

$15.2 \pm 2.1 \%$ ( $\mathrm{P}<0.01$ vs. ischemia); however, the miR-24 inhibitor did not change the rate of apoptosis ( $24.7 \pm 2.2 \%, \mathrm{P}>0.05$ vs. ischemia).

As determined by the Annexin V/PI dual staining (Fig. 5), a large percentage of $\mathrm{AV}^{-} / \mathrm{PI}^{-}$cells $(95.0 \pm 1.6 \%)$, and a small percentage of $\mathrm{AV}^{+} / \mathrm{PI}^{-}$ $(1.9 \pm 1.6 \%), \quad \mathrm{AV}^{+} / \mathrm{PI}^{+} \quad(2.2 \pm 0.5 \%)$ and $\quad \mathrm{AV}^{-} / \mathrm{PI}^{+}$ $(0.9 \pm 0.6 \%)$ cells were observed in normal cardiomyocyte cultures. After $24 \mathrm{~h}$ of ischemia, the percentage of $\mathrm{AV}^{-}$ $/ \mathrm{PI}^{-}$cells greatly decreased to $70.3 \pm 1.3 \%$ ( $\mathrm{P}<0.01$ vs. control), whereas the percentages of $\mathrm{AV}^{+} / \mathrm{PI}^{-}, \mathrm{AV}^{+} / \mathrm{PI}^{+}$ and $\mathrm{AV}^{-} / \mathrm{PI}^{+}$cells significantly increased to $12.9 \pm 1.1 \%$ ( $\mathrm{P}<0.01$ vs. control), $14.3 \pm 1.5 \%(\mathrm{P}<0.01$ vs. control) and $2.5 \pm 0.9 \%(\mathrm{P}<0.05$ vs. control), respectively, indicating significant apoptosis and necrosis. In normal cultures, transfection of the miR-24 mimic did not change the proportions of $\mathrm{AV}^{-} / \mathrm{PI}^{-}, \mathrm{AV}^{+} / \mathrm{PI}^{-}, \mathrm{AV}^{+} / \mathrm{PI}^{+}$or $\mathrm{AV}^{-} / \mathrm{PI}^{+}$ cells. However, under ischemic conditions, the miR-24 mimic significantly reduced the percentage of both

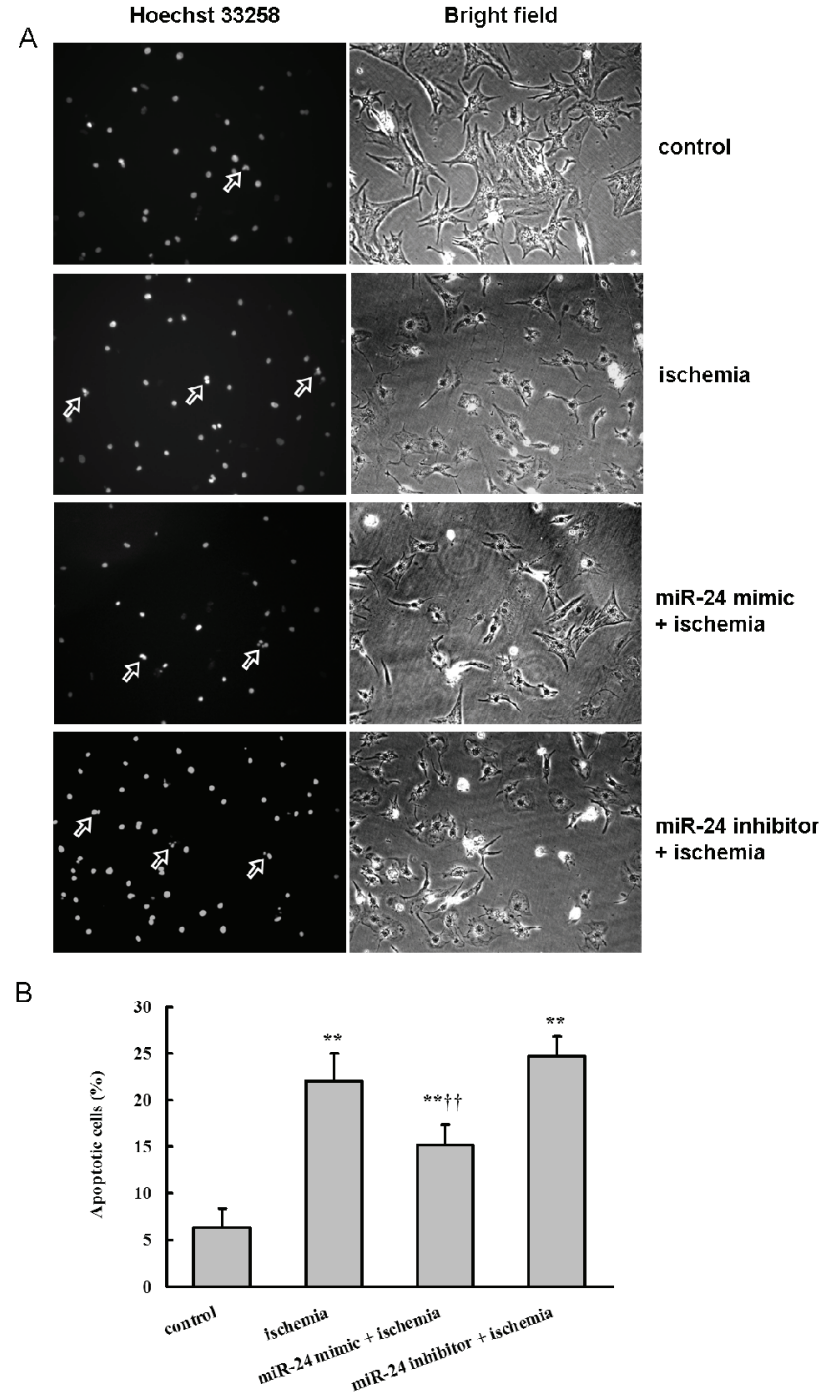

Fig. 4. Apoptotic cardiomyocytes detected by Hoechst 33258 dye staining after $24 \mathrm{~h}$ of mimic ischemia $\left(1 \% \mathrm{O}_{2}, 0.1 \%\right.$ glucose, serum-free). (A) Representative images of fluorescent staining with Hoechst 33258 (magnification 200x). Arrows indicate typical apoptotic myocytes. (B) Percentage of apoptotic cells versus total cells. Values are means \pm S.D. ( $n=3$ for each group). ${ }^{*} \mathrm{P}<0.05,{ }^{*} * \mathrm{P}<0.01$ vs. control; ${ }^{\dagger} \mathrm{P}<0.05,{ }^{+\dagger} \mathrm{P}<0.01$ vs. ischemia.

$\mathrm{AV}^{+} / \mathrm{PI}^{-}$and $\mathrm{AV}^{+} / \mathrm{PI}^{+}$cells to $6.9 \pm 1.4 \%(\mathrm{P}<0.01$ vs. ischemia) and $7.5 \pm 0.5 \% \quad(\mathrm{P}<0.01 \quad$ vs. ischemia $)$, respectively, indicating reduced apoptosis and necrosis. In myocytes transfected with miR-24 inhibitor, increased rates of both $\mathrm{AV}^{+} / \mathrm{PI}^{-}(8.2 \pm 1.5 \%, \mathrm{P}<0.01$ vs. control) and $\mathrm{AV}^{+} / \mathrm{PI}^{+}(11.4 \pm 3.4 \%, \mathrm{P}<0.01$ vs. control) cells were detected under normal conditions, with further increases in both rates detected under ischemia $\left(\mathrm{AV}^{+} / \mathrm{PI}^{-}\right.$ $17.0 \pm 5.4 \%, \quad \mathrm{AV}^{+} / \mathrm{PI}^{+} 18.7 \pm 2.4 \%$, both $\mathrm{P}<0.05$ vs. ischemia). These results showed that miR-24 inhibited ischemia-induced apoptosis and necrosis in cardiomyocytes, again providing support for a protective role of miR-24 in the heart. 
A
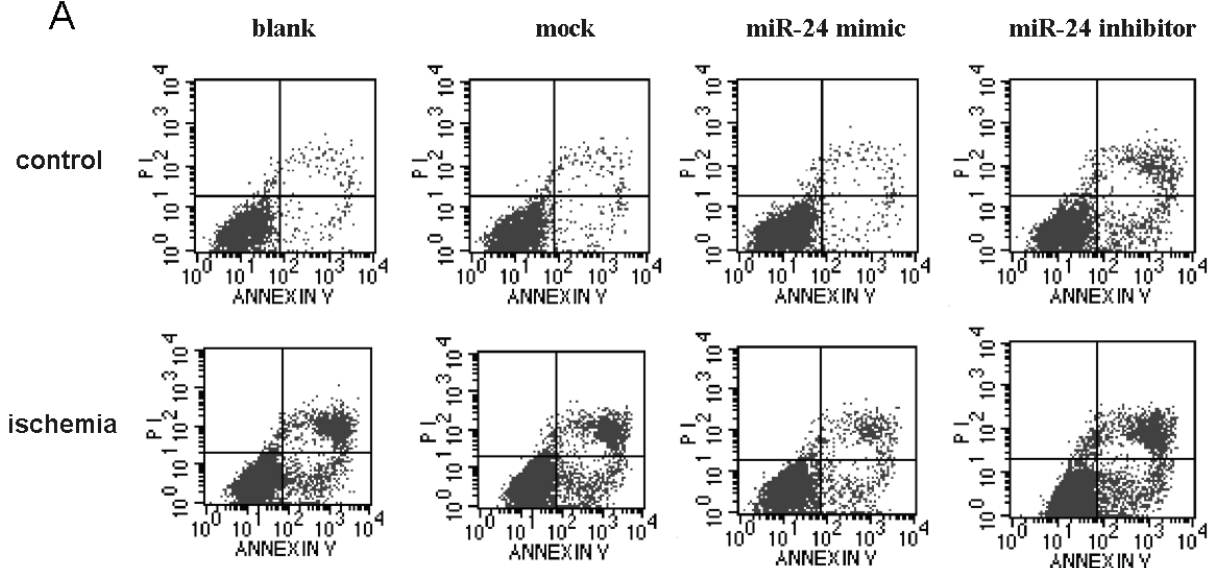

B

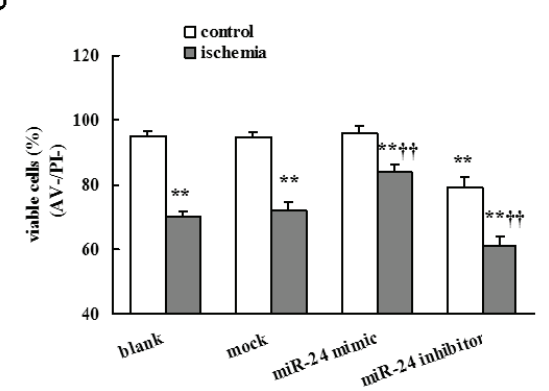

C

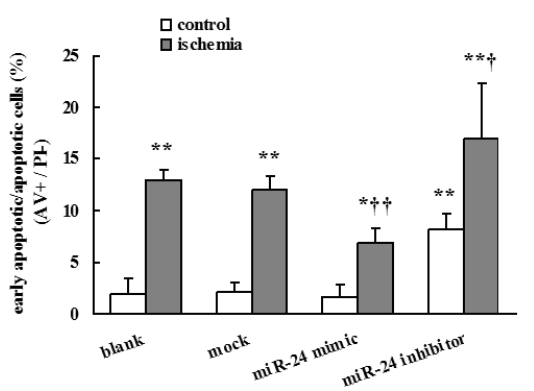

D

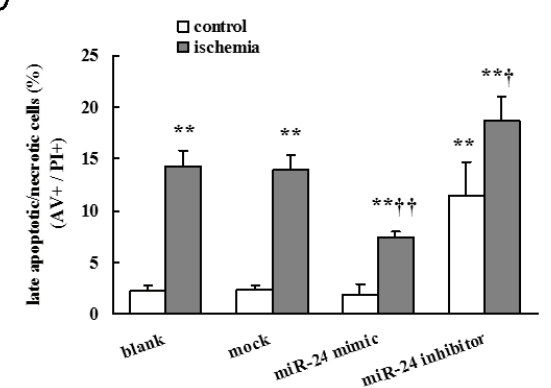

E

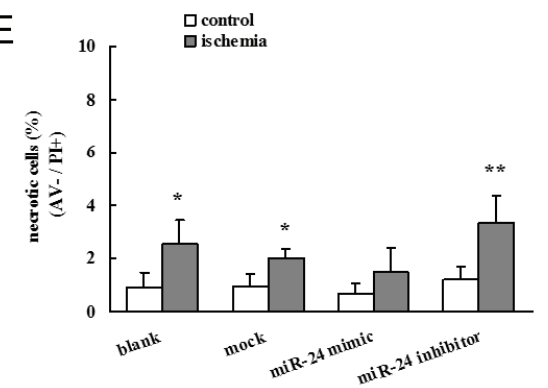

Fig. 5. Apoptosis and necrosis detected by Annexin V-FITC/propidium iodide (AV/PI) dual staining in primary cultured rat cardiomyocytes transfected with $100 \mathrm{nM}$ of the miR-24 mimic or inhibitor after $24 \mathrm{~h}$ of mimic ischemia (1\% $\mathrm{O}_{2}, 0.1 \%$ glucose, serum-free). (A) Representative dot-plot diagrams of AV/PI flow cytometry. The lower left quadrants contain the viable cells $\left(\mathrm{AV}^{-} / \mathrm{PI}^{-}\right)$, the lower right quadrants contain the early apoptotic/apoptotic cells $\left(\mathrm{AV}^{+} / \mathrm{PI}^{-}\right)$, the upper right quadrants contain the late apoptotic/necrotic cells $\left(\mathrm{AV}^{+} / \mathrm{PI}^{+}\right)$, and the upper left quadrants contain the necrotic cells $\left(\mathrm{AV}^{-} / \mathrm{PI}^{+}\right)$. (B-E) Percentage of $\mathrm{AV}^{-} / \mathrm{PI}^{-}$(B), $\mathrm{AV}^{+} / \mathrm{PI}^{-}$(C), $\mathrm{AV}^{+} / \mathrm{PI}^{+}$ (D), and $\mathrm{AV}^{-} / \mathrm{PI}^{+}$cells (E). Values are means \pm S.D. $(n=4$ for each group). $* \mathrm{P}<0.05, \quad * * \mathrm{P}<0.01$ vs. control; ${ }^{\dagger} \mathrm{P}<0.05,{ }^{+\dagger} \mathrm{P}<0.01$ vs. ischemia.
miR-24 inhibited the expression of the pro-apoptotic gene, BCL2L11

To investigate the mechanism through which miR-24 inhibited ischemic injury, we examined how miR-24 affects the expression of the pro-apoptotic gene BCL2L11, a potential target gene of miR-24 as predicted by bioinformatic algorithms (Fig. 6A).

A luciferase reporter fused with BCL2L11 3'-UTR that contains miR-24 binding sites was cotransfected with miR-24 mimic into $293 \mathrm{~T}$ cells for $24 \mathrm{~h}$. The luciferase activity assay showed that miR-24 mimic significantly decreased the activity of the luciferase reporter by $36 \%$ (Fig. 6B), suggesting the inhibition of miR-24 on BCL2L11 expression through its 3'-UTR.

The measurements of BCL2L11 mRNA level showed an increase of 3-fold in cultured myocytes exposed to ischemia ( $\mathrm{P}<0.01$ vs. control, Fig. 6C).
Transfection of the miR-24 inhibitor further enhanced the expression of BCL2L11 to 4.6-fold of the control level $(\mathrm{P}<0.01$ vs. ischemia, Fig. 6C). By contrast, the miR-24 mimic significantly reduced the expression of BCL2L11 to 2.0-fold of the control level $(\mathrm{P}<0.01$ vs. ischemia, Fig. 6C).

In accordance with the mRNA changes, similar changes in the protein levels of BCL2L11 were observed in response to miR-24 mimic or inhibitor transfection. The protein level of BCL2L11 was increased by 2.5 -fold under $24 \mathrm{~h}$ ischemic treatment $(\mathrm{P}<0.01$ vs. control, Fig. 6D,E), and was further increased to 3.4-fold of the control level by miR-24 inhibitor $(\mathrm{P}<0.05$ vs. ischemia, Fig. 6D,E). By contrast, the miR-24 mimic significantly reduced $\mathrm{BCL} 2 \mathrm{~L} 11$ protein amount to 1.8 -fold of the control level $(\mathrm{P}<0.01$ vs. ischemia, Fig. $6 \mathrm{D}, \mathrm{E})$. 


\begin{tabular}{|c|c|c|}
\hline BCL2L11 3' UTR & $\begin{array}{l}\text { predicted consequential pairing of target region } \\
\text { (top) and miR-24 (bottom) }\end{array}$ & $\begin{array}{c}\text { context } \\
\text { score }\end{array}$ \\
\hline Position 466-472 & $\ldots$. ACCCUGCAGUGGGAACUGAGCCA. . . & \\
\hline mo-miR-24 & $\begin{array}{cr}|||| \mid & |||||||| \\
\text { GACAAGGACGACUU----GACUCGGU }\end{array}$ & -0.3 \\
\hline Position 2826-2832 & $\begin{array}{r}5, \ldots \text { UgUUUCACUCGUCAACUGAGCCA. . } \\
|||||||| \mid\end{array}$ & -0.23 \\
\hline
\end{tabular}

B

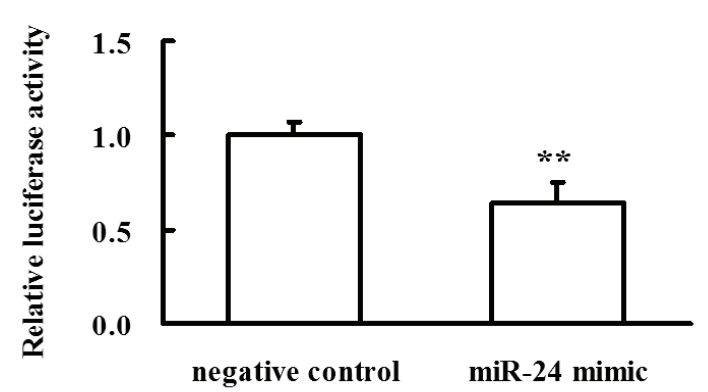

C

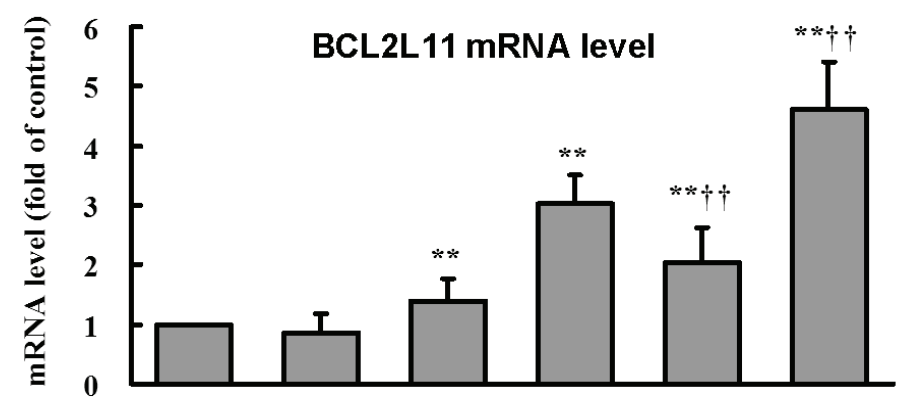

D
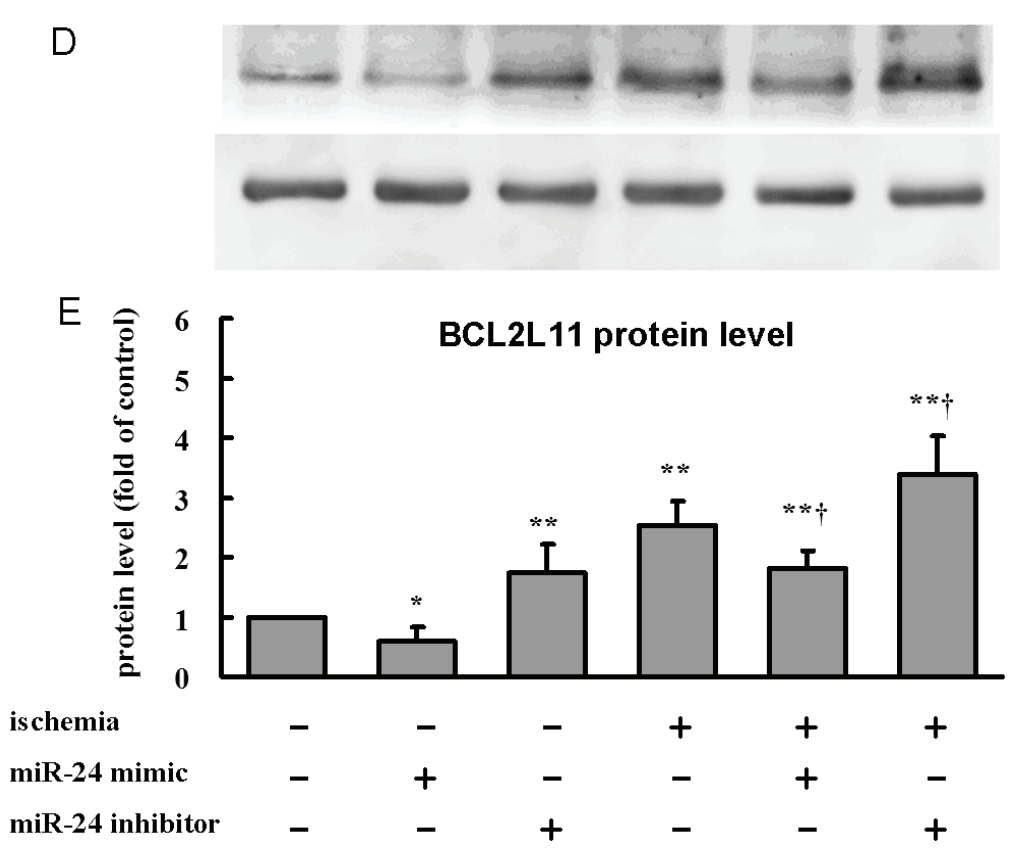

Fig. 6. Potential target genes of miR-24. (A) The potential binding sites between miR-24 and the mRNA 3' untranslated region (UTR) of BCL2L11 (source: www.targetscan.org). (B) Luciferase activity determined $24 \quad \mathrm{~h}$ after cotransfection of luciferase reporter plasmid containing BCL2L11 3'-UTR with miR-24 mimic into 293T cells. (C) The mRNA levels of BCL2L11 determined by real-time RT-PCR in normal and ischemic cardiomyocytes transfected with $100 \mathrm{nM}$ of the miR-24 mimic or inhibitor ( $\mathrm{n}=4$ for each group). (D) Representative western blot images for BCL2L11 and GAPDH in normal and ischemic cardiomyocytes transfected with the miR-24 mimic or inhibitor. (E) Quantitative data of BCL2L11 protein levels determined by western blot ( $n=3$ for each group). Values are means \pm S.D. $* P<0.05, * * P<0.01$ vs. control; ${ }^{\dagger} \mathrm{P}<0.05,{ }^{+\dagger} \mathrm{P}<0.01$ vs. ischemia.

\section{Discussion}

miRNAs are powerful new regulators of gene expression, potentially regulating more than $30 \%$ of protein-coding genes (Lewis et al. 2005). Previous studies have indicated that a variety of miRNAs are involved in myocardial ischemia (Dong et al. 2009, Hu et al. 2010, Qian et al. 2011). Using miRNA microarray technology, we found that the expression of miR-24 was significantly increased in rat myocardium after $4 \mathrm{~h}$ of 
ischemia (Fang et al. 2011). The upregulation of miR-24 in ischemic myocardium was confirmed by quantitative RT-PCR. Also, we observed the upregulation of miR-24 in primary cultured rat cardiomyocytes exposed to ischemia. When miR-24 was further overexpressed by its mimic sequence, a significant decrease in the rates of apoptosis and necrosis of ischemic myocytes was observed, as well as inhibited LDH release, and enhanced cell viability. Contrarily, the absence of miR-24 stimulated LDH release, reduced cell viability and increased apoptosis and necrosis in normal and ischemic myocytes.

The primary action of miRNAs is to promote target mRNA degradation and inhibit protein translation through interacting with the mRNA 3' UTR (Filipowicz et al. 2008). To explore the mechanism by which miR-24 protected ischemic cardiomyocytes, we searched for potential targets of miR-24 using bioinformatic algorithms, and many genes were included as its potential targets. Strikingly, among them there were two BCL2 family genes critically involved in apoptosis, the proapoptotic gene BCL2L11 (Bim) and the anti-apoptotic gene BCL2L2 (Bcl-W). Based on bioinformatic algorithms (Grimson et al. 2007), miR-24 theoretically has more potent effects on degrading BCL2L11 mRNA, since there are two conserved miR-24 binding sites with relatively favorable context scores in the 3' UTR of BCL2L11 mRNA. By comparison, there is only one site with an unfavorable score $(-0.15)$ in BCL2L2. In accordance with this, we found that miR-24 reduced both the mRNA and protein levels of BCL2L11, but did not affect the mRNA or protein level of BCL2L2 (data not shown). These results suggest that miR-24 protects ischemic cardiomyocytes by inhibiting the expression of the pro-apoptotic gene BCL2L11.

Coincidently, when we were preparing this manuscript, a new paper addressing miR-24 in mouse myocardial infarction was published (Qian et al. 2011). It reported that in vivo injection of miR-24 mimic along the border zone of an infarct inhibited cardiomyocyte apoptosis, reduced the infarct size and improved cardiac function in the mouse. The miR-24 inhibitor, however, caused apoptosis in normal cultured mouse cardiomyocytes. Even more coincidently, the aforementioned study (Qian et al. 2011) also identified Bim (BCL2L11) as a target of miR-24, but did not address whether miR-24 regulates the expression of BCL2L2. Our study further demonstrated the protective effects of miR-24 against myocardial ischemia by inhibiting BCL2L11 in rat cardiomyocytes. We observed that the miR-24 mimic inhibited both apoptosis and necrosis in ischemic myocytes, whereas the miR-24 inhibitor caused significant apoptosis and necrosis in normal myocytes, and aggravated apoptosis and necrosis in ischemic myocytes. Another recent study (Yin et al. 2008) supports our findings, with observations of increases in cardiac miR-24 in mice subjected to cytoprotective heat shock; this suggests a potential mediating role of miR-24 in cardioprotection.

The present study observed increased miR-24 in the ischemic area of rats $4 \mathrm{~h}$ after LAD ligation, as well as in cultured myocytes exposed to ischemia, which was dependent on HIF-1 activation. In addition, another study also showed miR-24 increased in response to low oxygen in multiple cancer cell lines via a HIF-1-dependent mechanism (Kulshreshtha et al. 2007). However, the study by Qian et al. (2011) observed decreases in miR-24 in the border zone of an infarct at 24 h, 3 days and 1 week after LAD ligation in mice. Similarly, Dong et al. (2009) reported decreases of miR-24 in the infarct area of rat hearts after $6 \mathrm{~h}$ ischemia. Such discrepancies have also been described for other miRNAs that changed upon myocardial ischemia, such as miR-1 (Ikeda et al. 2007, Yang et al. 2007, Dong et al. 2009). These discrepancies in miRNA expression might be associated with variations in species, cell types, sample localization and time points for sampling. The normalization standard used for miRNA quantification might also be a factor, but not a definitive factor. The present study and that by Qian et al. (2011) used the same standard - U6 - one of the most commonly used standards for miRNA experiments, and recently shown to be one of the most stable standards in ischemic-reperfused rat hearts (Brattelid et al. 2011). The different levels of miR-24 in ischemic myocardium between our study and the study by Qian et al. (2011) cannot be explained by standardization differences. Irrespective of this discrepancy, both studies showed miR-24 protected against myocardial ischemia.

In summary, miRNAs have emerged as important regulators of myocardial ischemia. Our study provides more data for the cardioprotective effects of miR-24 in ischemic injury. It may represent a potential novel therapeutic approach for treatment of ischemic heart disease in the future.

\section{Conflict of Interest}

There is no conflict of interest. 


\section{Acknowledgements}

This study was supported by grants from the National Basic Research Program of China (No. 2006CB503807, 2009CB521902), the National Natural Science Foundation of China (No. 30870906, 31071023), the Pujiang Project of Shanghai, China (No. 08PJ14001), the
Project Sponsored by the Scientific Research Foundation for the Returned Overseas Chinese Scholars, State Education Ministry, China (No. [2008] 891), and the Fund for Outstanding Young Teachers in Higher Education Institutions of Shanghai, China (No. [2009] 63).

\section{References}

BARTEL DP: MicroRNAs: Genomics, biogenesis, mechanism, and function. Cell 116: 281-297, 2004.

BERRA E, BENIZRI E, GINOUVÈS A, VOLMAT V, ROUX D, POUYSSÉGUR J: HIF prolyl-hydroxylase 2 is the key oxygen sensor setting low steady-state levels of HIF-1 $\alpha$ in normoxia. EMBO J 22: 4082-4090, 2003.

BRATTELID T, AARNES EK, HELGELAND E, GUVAÅG S, EICHELE H, JONASSEN AK: Normalization strategy is critical for the outcome of miRNA expression analyses in the rat heart. Physiol Genomics 43: 604-610, 2011.

CARÈ A, CATALUCCI D, FELICETTI F, BONCI D, ADDARIO A, GALLO P, BANG ML, SEGNALINI P, GU Y, DALTON ND, ELIA L, LATRONICO MV, HØYDAL M, AUTORE C, RUSSO MA, DORN GW 2ND, ELLINGSEN O, RUIZ-LOZANO P, PETERSON KL, CROCE CM, PESCHLE C, CONDORELLI G: MicroRNA-133 controls cardiac hypertrophy. Nature Med 13: 613-618, 2007.

DONG S, CHENG Y, YANG J, LI J, LIU X, WANG X, WANG D, KRALL TJ, DELPHIN ES, ZHANG C: MicroRNA expression signature and the role of microRNA-21 in the early phase of acute myocardial infarction. J Biol Chem 284: 29514-29525, 2009.

FANG J, SONG XW, TIAN J, CHEN HY, LI DF, WANG JF, REN AJ, YUAN WJ, LIN L: Overexpression of microRNA-378 attenuates ischemia-induced apoptosis by inhibiting caspase-3 expression in cardiac myocytes. Apoptosis 17: 410-423, 2012.

FILIPOWICZ W, BHATTACHARYYA SN, SONENBERG N: Mechanisms of post-transcriptional regulation by microRNAs: are the answers in sight? Nat Rev Genet 9: 102-114, 2008.

GRIMSON A, FARH KK, JOHNSTON WK, GARRETT-ENGELE P, LIM LP, BARTEL DP: MicroRNA targeting specificity in mammals: Determinants beyond seed pairing. Mol Cell 27: 91-105, 2007.

HE J, GU D, WU X, REYNOLDS K, DUAN X, YAO C, WANG J, CHEN CS, CHEN J, WILDMAN RP, KLAG MJ, WHELTON PK: Major causes of death among men and women in China. N Engl J Med 53: 1124-1134, 2005.

HU S, HUANG M, LI Z, JIA F, GHOSH Z, LIJKWAN MA, FASANARO P, SUN N, WANG X, MARTELLI F, ROBBINS RC, WU JC: MicroRNA-210 as a novel therapy for treatment of ischemic heart disease. Circulation 122: S124-S131, 2010.

IKEDA S, KONG SW, LU J, BISPING E, ZHANG H, ALLEN PD, GOLUB TR, PIESKE B, PU WT: Altered microRNA expression in human heart disease. Physiol Genomics 31: 367-373, 2007.

KULSHRESHTHA R, FERRACIN M, WOJCIK SE, GARZON R, ALDER H, AGOSTO-PEREZ FJ, DAVULURI R, LIU CG, CROCE CM, NEGRINI M, CALIN GA, IVAN M: A microRNA signature of hypoxia. Mol Cell Biol 27: 1859-1867, 2007.

LATRONICO M, CATALUCCI D, CONDORELLI G: Emerging role of microRNAs in cardiovascular biology. Circ Res 101: 1225-1236, 2007.

LEWIS BP, BURGE CB, BARTEL DP: Conserved seed pairing, often flanked by adenosines, indicates that thousands of human genes are microRNA targets. Cell 120: 15-20, 2005.

LIN L, YUAN WJ: Effects of different preproendothelin-1 mRNA anti-sense oligodeoxynucleotides on ischemic arrhythmias in rats. J Cardiovasc Pharmacol 39: 590-599, 2002.

MABJEESH NJ, ESCUIN D, LAVALLEE TM, PRIBLUDA VS, SWARTZ GM, JOHNSON MS, WILLARD MT, ZHONG H, SIMONS JW, GIANNAKAKOU P: 2ME2 inhibits tumor growth and angiogenesis by disrupting microtubules and dysregulating HIF. Cancer Cell 3: 363-375, 2003. 
PAN YX, REN AJ, ZHENG J, RONG WF, CHEN C, YAN XH, WU C, YUAN WJ, LIN L: Delayed cytoprotection induced by hypoxic preconditioning in cultured neonatal rat cardiomyocytes: role of GRP78. Life Sci 81: 10421049, 2007.

QIAN L, VAN LAAKE LW, HUANG Y, LIU S, WENDLAND MF, SRIVASTAVA D: miR-24 inhibits apoptosis and represses Bim in mouse cardiomyocytes. J Exp Med 208: 549-560, 2011.

SONG XW, LI Q, LIN L, WANG XC, LI DF, WANG GK, REN AJ, WANG YR, QIN YW, YUAN WJ, JING Q: MiRNAs are dynamically regulated in hypertrophic hearts, and miR-199a is essential for the maintenance of cell size in cardiomyocytes. J Cell Physiol 225: 437-443, 2010.

THUM T, GALUPPO P, WOLF C, FIEDLER J, KNEITZ S, VAN LAAKE LW, DOEVENDANS PA, MUMMERY CL, BORLAK J, HAVERICH A, GROSS C, ENGELHARDT S, ERTL G, BAUERSACHS J: MicroRNAs in the human heart: a clue to fetal gene reprogramming in heart failure. Circulation 116: 258-267, 2007.

VAN ROOIJ E, OLSON EN: MicroRNAs: powerful new regulators of heart disease and provocative therapeutic targets. J Clin Invest 117: 2369-2376, 2007.

YANG B, LIN H, XIAO J, LU Y, LUO X, LI B, ZHANG Y, XU C, BAI Y, WANG H, CHEN G, WANG Z: The muscle-specific microRNA miR-1 regulates cardiac arrhythmogenic potential by targeting GJA1 and KCNJ2. Nature Med 13: 486-491, 2007.

YE Y, PEREZ-POLO JR, QIAN J, BIRNBAUM Y: The role of microRNA in modulating myocardial ischemiareperfusion injury. Physiol Genomics 43: 534-542, 2011.

YIN C, WANG X, KUKREJA RC: Endogenous microRNAs induced by heat-shock reduce myocardial infarction following ischemia-reperfusion in mice. FEBS Lett 582: 4137-4142, 2008.

ZHENG J, FANG J, YIN YJ, WANG XC, REN AJ, BAI J, SUN XJ, YUAN WJ, LIN L: Leptin protects cardiomyocytes from serum-deprivation-induced apoptosis by increasing anti-oxidant defence. Clin Exp Pharmacol Physiol 37: 955-962, 2010. 